\title{
Rastreability of bovine meat and bone meal using the stable isotope technique in egg
}

\section{production}

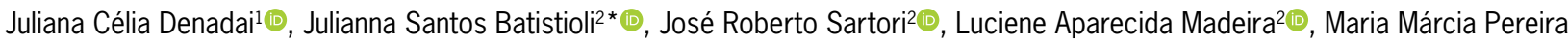 \\ Sartori ${ }^{4 \oplus}$, Carla Cachoni Pizzolante ${ }^{5} \odot$, Sérgio Kenji Kakimoto ${ }^{\circledR \odot}$, Armando Carlos Contin Neto ${ }^{2}$, Vladimir Eliodoro Costa ${ }^{1}$
}

"Universidade Estadual Paulista "Júlio de Mesquita Filho"/ IB - Centro de Isótopos Estáveis, R. Prof. Dr. Antônio Celso Wagner Zanin, 250 - 18618-689 - Botucatu, SP - Brasil. 2Universidade Estadual Paulista "Júlio de Mesquita Filho"/ FMVZ - Depto. de Melhoramento e Nutrição Animal, R. Prof. Dr. Walter Mauricio Correa, s/n - 18618-681 - Botucatu, SP - Brasil.

${ }^{3}$ Granja Kakimoto, Estrada Seção Cascata, km 7 - 17690000 - Bastos, SP - Brasil.

${ }^{4}$ Universidade Estadual Paulista Júlio de Mesquita Filho/ FCA - Depto. de Produção e Melhoramento Vegetal, R. Prof. Dr. Walter Mauricio Correa, s/n-18618-681 - Botucatu, SP - Brasil.

5nstituto de Zootecnia, R. Heitor Penteado, 56 - 13380-011

- Nova Odessa, SP - Brasil.

*Corresponding author <julianna.agro@hotmail.com>

Edited by: Gerson Barreto Mourão

Received October 31, 2019

Accepted August 25, 2020
ABSTRACT: The present study aimed to verify whether the inclusion of other ingredients in the diet of laying hens could interfere with the traceability of bovine meat and bone meal (BMBM) in eggs through stable carbon and nitrogen isotope analysis. Two hundred and fifty-six white laying hens were used and randomly distributed into eight treatments composed of: CONTROL: control diet; GLUTEN: control diet + corn gluten; YEAST: control diet + yeast; GLUTEN + YEAST: control diet + corn gluten + yeast; BMBM: control diet + 4.5\% BMBM; BMBM + GLUTEN: control diet + corn gluten + $4.5 \%$ BMBM; BMBM + YEAST: control diet + yeast + $4.5 \%$ BMBM; BMBM + GLUTEN + YEAST: control diet + corn gluten + yeast + 4.5\% BMBM. The isotopic results were subjected to multivariate analysis of variance (MANOVA) and LDA multivariate linear discriminant analysis. At 28 days, the eggs of the birds given diets without the addition of BMBM differed from the CONTROL group. The yolks showed that all treatments were significantly different from the CONTROL, and at 56 days, all eggs and egg yolks were different from the CONTROL. At 28 days, albumen was significantly different for all CONTROL experimental treatments; however, at 56 days, the YEAST treatment showed no difference from the control. Thus, it was concluded that even with the addition of other ingredients, the isotope technique is still able to detect the BMBM in eggs.

Keywords: albumen, carbon-13, nitrogen-15, traceability, yolk

\section{Introduction}

Currently, Brazil is the third largest world producer of chicken meat and has one of the most productive commercial poultry industries in the world, becoming the largest poultry exporter in 2004. The use of diets containing meat, viscera and feather meal as a protein source for the feeding of monogastrics as a replacement for soybean meal is common in Brazilian integration companies due to their relatively low cost and beneficial source of nutrients if properly processed (Bellaver et al., 2001).

According to Verbeke and Ward (2006), traceability is the guarantee given to the consumer that he/she is consuming a product that is controlled at all stages of production. Traceability is an increasingly important tool because it favors the consumer's preferences and satisfaction and is a result of growing concern about food safety and quality in addition to being the basis for the implementation of a quality control program that spans the entire production chain (Chen and Huang, 2013; Menozzi et al., 2015).

Continuous improvement of the certification process of poultry meat can protect the Brazilian poultry industry from the threat of imposition of non-tariff barriers by importing countries, and it also acts as a tool for the exploration and conquest of new market niches (Oliveira et al., 2010).
The carbon isotope ratio in association with the nitrogen isotope ratio enables the identification of the presence of bovine meat and bone meal (BMBM) (Carrijo et al., 2006), poultry viscera meal (Oliveira et al., 2010), poultry viscera meal and BMBM together with yeast and wheat bran (Gottmann et al., 2008) in the feed of broiler chickens.

In the present study, only corn, soybean meal and increasing levels of BMBM were used as the major ingredients of the diets to avoid greater interference caused by the use of a large number of ingredients. Therefore, there is a need to verify whether these other ingredients could interfere in the detection of BMBM, because Madeira et al. (2015) studied the same ingredients but their lower inclusion and low inclusion were not differentiated from BMBM. Thus, the present study aimed to verify whether the inclusion of other ingredients, such as wheat bran, corn gluten and yeast in the diets of laying hens affects the traceability of bovine meat and bone meal in eggs using stable carbon and nitrogen isotope analysis.

\section{Materials and Methods}

The experiment was conducted in Botucatu, São Paulo, Brazil, (22 $51^{\prime} 28.1^{\prime \prime} \mathrm{S} 48^{\circ} 26^{\prime} 02.8^{\prime \prime} \mathrm{W}$, altitude of $\left.786 \mathrm{~m}\right)$ in partnership with São Paulo, Brazil, $\left(22^{\circ} 17^{\prime} 32.1^{\prime \prime}\right.$ S $48^{\circ} 07^{\prime} 48.6^{\prime \prime} \mathrm{W}$, altitude of $609 \mathrm{~m}$ ). 
Two hundred and fifty-six Bovan white laying hens, 27 weeks of age, were used and randomly distributed in eight treatment groups with four replicates. A cage with a density of eight birds was considered to be one replicate.

The treatments comprised a control diet based on corn, soybean meal and wheat bran, and the other diets were supplemented with corn gluten and/or yeast and/ or bovine meat and bone meal (BMBM: control diet + $4.5 \% \mathrm{BMBM}$ ) according to the following description:

CONTROL: control diet;

GLUTEN: control diet + corn gluten;

YEAST: control diet + yeast;

GLUTEN + YEAST: control diet + corn gluten + yeast; BMBM: control diet $+4.5 \%$ BMBM;

BMBM + GLUTEN: control diet + corn gluten + $4.5 \%$ BMBM;

BMBM + YEAST: control diet + yeast + $4.5 \%$ BMBM;

BMBM + GLUTEN + YEAST: control diet + corn gluten + yeast $+4.5 \%$ BMBM

Two different lots of corn, soybean meal and wheat bran were acquired so that the experimental conditions were as similar as possible to the reality on farms, that is, the constant receipt of ingredients from different producers, which may cause variations in the isotope signal. These variations were especially noticeable in the $\delta^{15} \mathrm{~N}$ values (\%o) due to the different fertilising conditions and types of soil. Two batches of each diet were prepared, the first batch for poultry feeding from 1-28 days with the first lot of corn, soybean meal and wheat bran and the second batch with the second lot of ingredients for the period between 29 and 56 days.

To simulate what happens on the farms, the diet mixtures were administered weekly, using the ingredients contained in the feed mill, since the first studies of the research team used the same ingredient from the beginning to the end of the study. To also test the isotopic changes found in the acquisition of ingredients from different locations the ingredients used in the preparation of the experimental diets were calculated to determine the estimated values of protein, calcium, phosphorus, metabolized energy and amino acids composition presented by Rostagno et al. (2011). The isotopic values of the ingredients were analysed in an isotope ratio mass spectrometer (Table 1). The diets (Table 2) were formulated and balanced so that their contents were isocaloric, isonitrogenic, isocalcic, isophosphoric and iso-amino acidic for methionine + cystine and lysine, according to the nutritional recommendation of Rostagno et al. (2011).

Before the beginning of the experiment, eight eggs per treatment were sampled and used to measure the average isotope signal in the eggs $\left(\delta^{13} \mathrm{C}=-18 \pm\right.$ 0.2 and $\left.\delta^{15} \mathrm{~N}=5.2 \pm 0.1\right)$, and eight were used for individual analysis of the egg yolks $\left(\delta^{13} \mathrm{C}=-18 \pm 0.1\right.$ and $\left.\delta^{15} \mathrm{~N}=4.8 \pm 0.2\right)$ and the albumen $\left(\delta^{13} \mathrm{C}=-17.9\right.$ \pm 0.1 and $\delta^{15} \mathrm{~N}=5.3 \pm 0.1$ ).

In two consecutive 28-day interval cycles 16 eggs per treatment were selected randomly, when eight eggs

Table 1 - Average $\delta^{13} \mathrm{C}$ and $\delta^{15} \mathrm{~N}$ isotope values (mean \pm SD) of the ingredients and diets. $(n=2)$.

\begin{tabular}{|c|c|c|c|c|}
\hline \multirow{2}{*}{ Ingredients } & \multicolumn{2}{|c|}{ 1-28 days } & \multicolumn{2}{|l|}{ 29-56 days } \\
\hline & $\delta^{13} \mathrm{C}$ & $\delta^{15} \mathrm{~N}$ & $\delta^{13} \mathrm{C}$ & $\delta^{15} \mathrm{~N}$ \\
\hline Corn 1 & $-12.33 \pm 0.04$ & $4.56 \pm 0.18$ & & \\
\hline Corn 2 & & & $-12.30 \pm 0.02$ & $5.50 \pm 0.02$ \\
\hline Soybean meal - 45 \%CP 1 & $-25.83 \pm 0.01$ & $0.59 \pm 0.12$ & & \\
\hline Soybean meal - 45 \%CP 2 & & & $-27.75 \pm 0.04$ & $0.65 \pm 0.22$ \\
\hline Wheat bran 1 & $27.74 \pm 0.12$ & $2.95 \pm 0.15$ & & \\
\hline Wheat bran 2 & & & $-26.78 \pm 0.04$ & $3.40 \pm 0.15$ \\
\hline $\mathrm{BMBM}-40 \% \mathrm{CP}$ & $-12.94 \pm 0.00$ & $7.33 \pm 0.16$ & $-12.94 \pm 0.00$ & $7.33 \pm 0.16$ \\
\hline Corn gluten & $-14.46 \pm 0.01$ & $4.03 \pm 0.09$ & $-14.46 \pm 0.01$ & $4.03 \pm 0.09$ \\
\hline Yeast & $-10.16 \pm 0.02$ & $4.49 \pm 0.02$ & $-10.16 \pm 0.02$ & $4.49 \pm 0.02$ \\
\hline \multicolumn{5}{|l|}{ Treatments } \\
\hline CONTROL & $-17.02 \pm 0.03$ & $1.91 \pm 0.17$ & $-18.15 \pm 0.34$ & $1.96 \pm 0.13$ \\
\hline GLUTEN & $-15.93 \pm 0.11$ & $2.69 \pm 0.19$ & $-16.38 \pm 0.57$ & $2.47 \pm 0.13$ \\
\hline YEAST & $-16.27 \pm 0.07$ & $2.44 \pm 0.08$ & $-16.53 \pm 0.05$ & $2.34 \pm 0.04$ \\
\hline GLUTEN + YEAST & $-16.40 \pm 0.18$ & $2.75 \pm 0.06$ & $-15.97 \pm 0.15$ & $2.47 \pm 0.11$ \\
\hline BMBM & $-15.77 \pm 0.13$ & $2.83 \pm 0.03$ & $-16.52 \pm 0.25$ & $2.95 \pm 0.08$ \\
\hline BMBM + GLUTEN & $-15.34 \pm 0.11$ & $3.18 \pm 0.08$ & $-14.79 \pm 0.04$ & $3.17 \pm 0.02$ \\
\hline$B M B M+Y E A S T$ & $-15.69 \pm 0.07$ & $3.18 \pm 0.08$ & $-15.85 \pm 0.16$ & $3.57 \pm 0.17$ \\
\hline BMBM + GLUTEN + YEAST & $-14.90 \pm 0.04$ & $3.48 \pm 0.13$ & $-14.49 \pm 0.26$ & $3.19 \pm 0.09$ \\
\hline
\end{tabular}


Table 2 -The percentage composition of the ingredients used and nutritional levels.

\begin{tabular}{|c|c|c|c|c|c|c|c|c|}
\hline \multirow[b]{2}{*}{ Ingredients } & \multicolumn{8}{|c|}{ DIETS (\%) } \\
\hline & CONTROL & GLUTEN & YEAST & $\begin{array}{l}\text { GLUTEN + } \\
\text { YEAST }\end{array}$ & BMBM & $\begin{array}{l}\text { BMBM + } \\
\text { GLUTEN }\end{array}$ & $\begin{array}{l}\text { BMBM + } \\
\text { YEASTA }\end{array}$ & $\begin{array}{c}\text { BMBM + GLUTEN + } \\
\text { YEAST }\end{array}$ \\
\hline Corn & 58.87 & 61.33 & 58.19 & 60.64 & 62.14 & 63.47 & 61.43 & 62.79 \\
\hline Soybean meal (45 \% CP) & 27.35 & 22.93 & 25.06 & 20.63 & 22.33 & 18.05 & 20.03 & 15.81 \\
\hline Wheat bran & 1.00 & 1.00 & 1.00 & 1.00 & 1.00 & 1.00 & 1.00 & 1.00 \\
\hline Bovine meat bone meal ( $40 \% \mathrm{CP}$ ) & - & - & - & - & 4.50 & 4.50 & 4.50 & 4.50 \\
\hline Corn gluten & - & 3.00 & - & 3.00 & - & 3.00 & - & 3.00 \\
\hline Yeast & - & - & 3.00 & 3.00 & - & - & 3.00 & 3.00 \\
\hline Oil soybean & 1.90 & 0.84 & 1.90 & 0.84 & 0.68 & - & 0.69 & - \\
\hline Limestone & 8.70 & 8.72 & 8.70 & 8.72 & 8.36 & 8.36 & 8.37 & 8.37 \\
\hline Dicalcium phosphate & 1.53 & 1.55 & 1.51 & 1.54 & 0.34 & 0.40 & 0.33 & 0.37 \\
\hline DL-Methionine & 0.15 & 0.13 & 0.14 & 0.13 & 0.15 & 0.13 & 0.15 & 0.13 \\
\hline L-Lysine & - & - & - & - & - & 0.04 & - & - \\
\hline Choline chloride & 0.05 & 0.05 & 0.05 & 0.05 & 0.05 & 0.05 & 0.05 & 0.05 \\
\hline Salt & 0.30 & 0.30 & 0.30 & 0.30 & 0.30 & 0.30 & 0.30 & 0.30 \\
\hline Vitamin supplement ${ }^{1}$ & 0.10 & 0.10 & 0.10 & 0.10 & 0.10 & 0.10 & 0.10 & 0.10 \\
\hline Mineral supplement ${ }^{2}$ & 0.05 & 0.05 & 0.05 & 0.05 & 0.05 & 0.05 & 0.05 & 0.05 \\
\hline Kaolin & - & - & - & - & - & 0.55 & - & 0.53 \\
\hline TOTAL & 100.00 & 100.00 & 100.00 & 100.00 & 100.00 & 100.00 & 100.00 & 100.00 \\
\hline \multicolumn{9}{|l|}{ Calculated composition } \\
\hline Metabolizable energy $\left(\mathrm{kcal}^{-1}\right)$ & $2,799.95$ & $2,800.14$ & $2,799.99$ & $2,800.10$ & $2,800.04$ & $2,800.09$ & $2,800.21$ & $2,800.24$ \\
\hline Crude protein (\%) & 17.50 & 17.50 & 17.50 & 17.50 & 17.50 & 17.50 & 17.50 & 17.50 \\
\hline Calcium (\%) & 3.80 & 3.80 & 3.80 & 3.80 & 3.80 & 3.80 & 3.80 & 3.80 \\
\hline Available phosphorus (\%) & 0.38 & 0.38 & 0.38 & 0.38 & 0.38 & 0.38 & 0.38 & 0.38 \\
\hline Crude fiber (\%) & 2.59 & 2.43 & 2.47 & 2.31 & 2.38 & 2.20 & 2.26 & 2.09 \\
\hline Digestible metionine \% & 0.43 & 0.42 & 0.42 & 0.43 & 0.43 & 0.42 & 0.43 & 0.42 \\
\hline Digestible metionine+cystine (\%) & 0.71 & 0.72 & 0.70 & 0.72 & 0.71 & 0.71 & 0.70 & 0.71 \\
\hline Digestible lysine (\%) & 0.91 & 0.82 & 0.93 & 0.84 & 0.87 & 0.82 & 0.90 & 0.82 \\
\hline
\end{tabular}

'Vitamin supplement (levels per kg of diet): Vitamin $\mathrm{A}=7.000 \mathrm{Ul}$; Vitamin D3 = $2.000 \mathrm{Ul}$; Vitamin $\mathrm{E}=5 \mathrm{mg}$; Vitamin K3 = $1.6 \mathrm{mg}$; Vitamin B2 = $3 \mathrm{mg}$; Vitamin B12 $=8 \mathrm{mcg}$; Calcium Pantothenate $=5 \mathrm{mg}$; Niacin $=20 \mathrm{mg}$; Antioxidant = $15 \mathrm{mg}$; ${ }^{2}$ Mineral supplement (levels per $\mathrm{kg}$ of diet): Copper $=8 \mathrm{mg}$; iron $=50 \mathrm{mg}$; lodine $=$ $1.2 \mathrm{mg}$; Manganese $=70 \mathrm{mg}$; Zinc $=50 \mathrm{mg}$; Selenium $=0.2 \mathrm{mg}$.

were used to collect samples of the yolk and albumen and the remaining eight were used for analysis of the whole egg.

The samples were processed and analysed for isotopes according to the methods described by Denadai et al. (2009). In order to take measurements of the isotopic abundance of a manageable magnitude, the isotopic composition of most materials is expressed as the normalized ratio of the sample to a standard in parts per thousand (per mil, \%o) (Equation 1):

$\delta X=\left[\left(\frac{\text { Rsample }}{\text { Rstandard }}\right)-1\right] * 1000$

where $\mathrm{R}$ sample and $\mathrm{R}$ standard are the ratios of heavy isotopes for the sample and the standard, respectively. Atmospheric nitrogen and a marine carbonate from a belemnite from the Peedee Formation (PDB) were used as the standards for nitrogen and carbon, respectively.

To verify the normality of the data, the ShapiroWilk test was used. The normality tests were performed with a $95 \%$ degree of confidence (significance level $(\alpha)$ of $5 \%$ ). The isotopic results were subjected to a multivariate analysis of variance (MANOVA) with the aid of the general linear model (GLM) procedure from the SAS statistical software package and the multivariate linear discriminant analysis program (LDA) in the Minitab 16 statistical package (2010).

\section{Results}

There was an isotopic difference for $\delta^{13} \mathrm{C}$ and $\delta^{15} \mathrm{~N}$ between the formulated feed diets from 1 to 28 days (corn, soybean meal and wheat bran 1) and again from 29 to 56 days (corn, soybean meal and wheat bran 2) of the experiment. This outcome may be a consequence of the isotopic variation of the ingredients used in the diets (Table 1). The difference in $\delta^{13} \mathrm{C}$ resulted mainly from the depletion of soybean meal 2, while the difference in $\delta^{15} \mathrm{~N}$ was due to the enrichment of corn 2 and wheat bran 2 .

There were also differences in the isotopic $\delta^{13} \mathrm{C}$ and $\delta^{15} \mathrm{~N}$ of eggs and fractions between the two experimental periods from day 1 to 28 days and day 29 to 56 days. Calculations were also different for the isotopic fractionation between the evaluation periods for eggs and its fractions in all treatments (1-28 days 
and 29-56 days) and was calculated to find the best day on which to collect samples for the traceability process after changing the diet. The average values of $\delta^{13} \mathrm{C}$ and $\delta^{15} \mathrm{~N}$ for the total egg (yolk + albumen) were statistically analysed; they generated regions with 95 $\%$ confidence (Figure 1A, B, C and D) and response groups by discriminant analysis.

On day 28 , the eggs of birds fed with diets without animal-origin flour were only different in carbon-13 from those of the control group (Figure 1A) because of the confidence regions touching the axis of the plot at zero difference for nitrogen-15. Of all the treatments supplemented with BMBM (Figure 1C), only the BMBM (control diet $+4.5 \%$ BMBM) treatment was significantly different from the CONTROL (control diet) and only for carbon-13, while the other treatments showed differences for both isotopes. However, by day
56, all eggs were different from the control treatment (Figure $1 \mathrm{~B}$ and D).

The discriminant analysis of eggs assessed at 28 days indicated that the control group formed a response group with seven samples. The GLUTEN (control diet + corn gluten) and GLUTEN + YEAST (control diet + corn gluten + yeast) groups formed a response group with its respective eight samples. The YEAST (control diet + yeast) treatment formed a response group with seven samples of YEAST (control diet + yeast), one CONTROL (control diet) sample and one BMBM (control diet $+4.5 \%$ BMBM) sample. The BMBM (control diet $+4.5 \%$ BMBM) response group was formed by seven BMBM (control diet $+4.5 \%$ BMBM) samples and one YEAST (control diet + yeast) sample, while the other response groups of the treatments supplemented with BMBM (control diet $+4.5 \%$ BMBM) formed groups
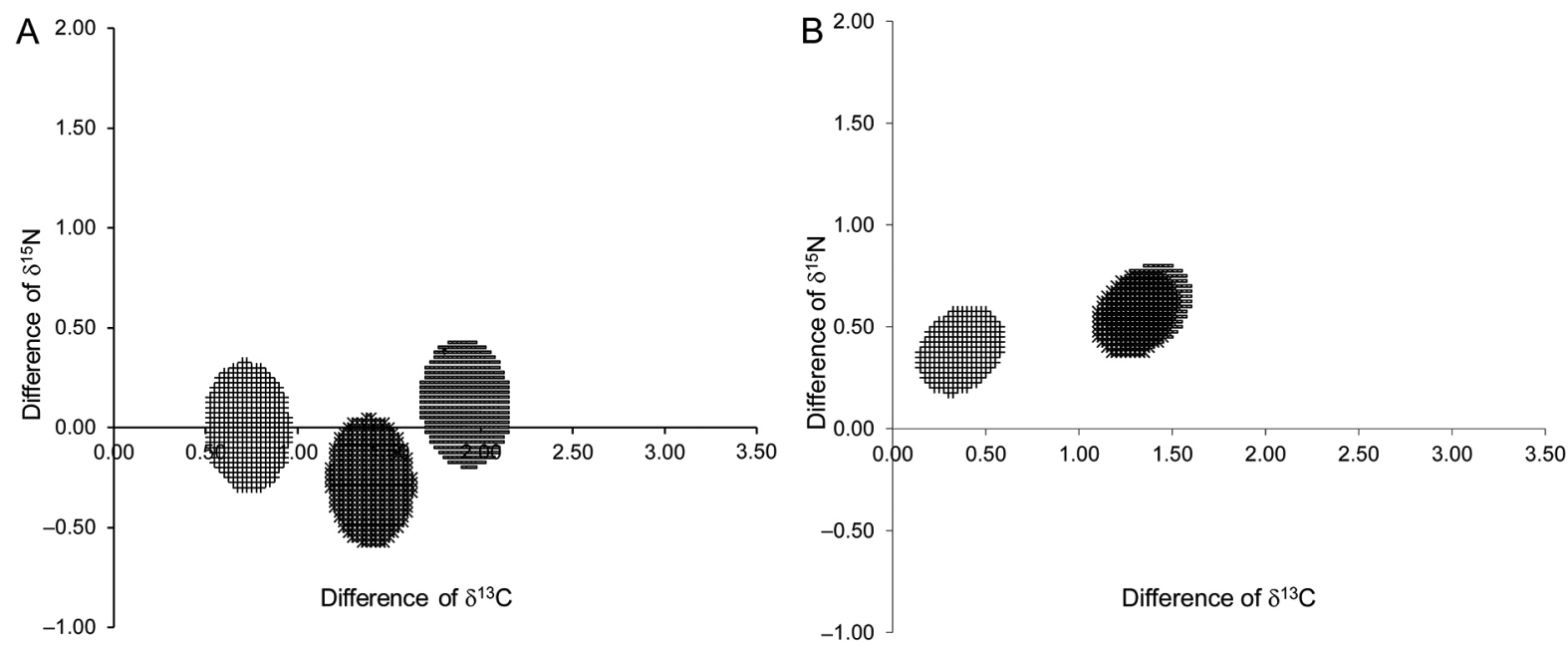

*GLUTEN + YEAST - GLUTEN+YEAST
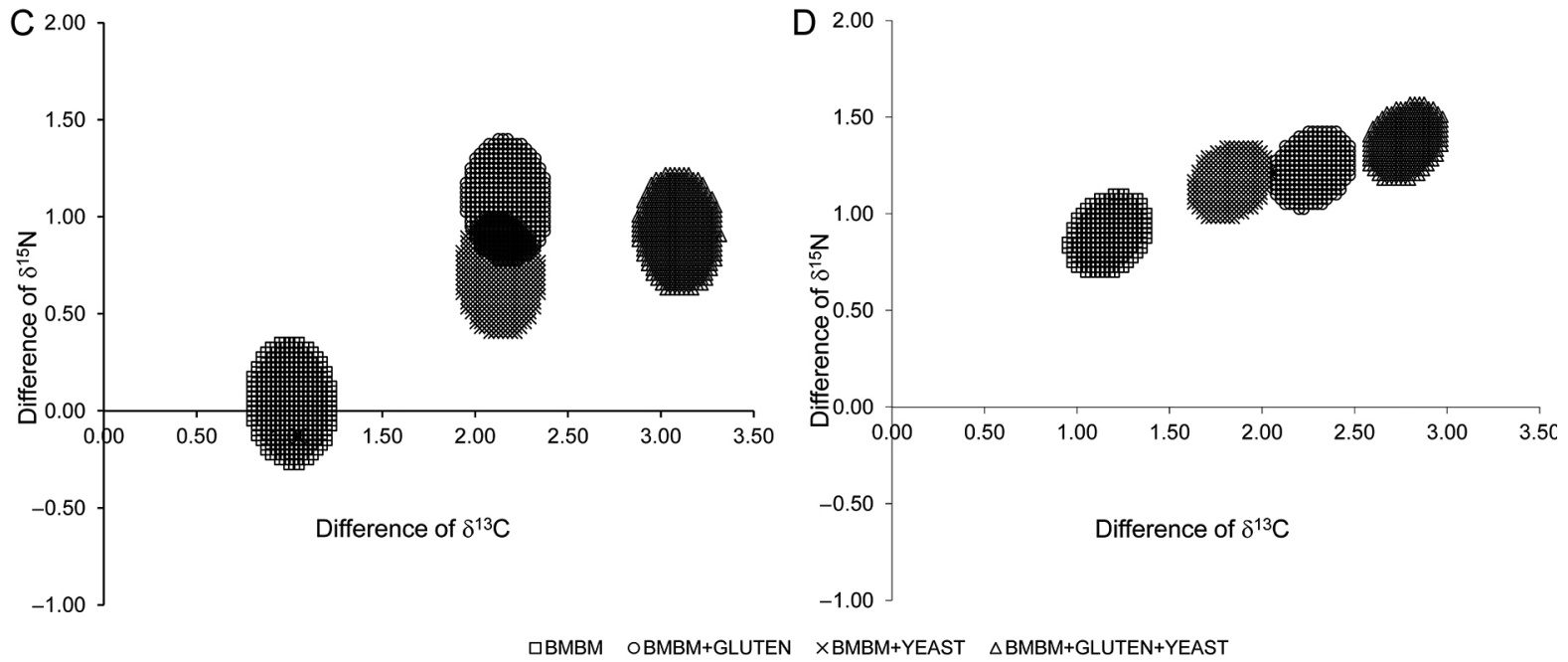

Figure 1 - The confidence regions formed by the difference between the $\delta^{13} \mathrm{C}$ and $\delta^{15} \mathrm{~N}$ isotope values of the eggs in each treatment group compared to the control treatment group $(n=8)$. A) 28 days; B) 56 days; C) 28 days; D) 56 days. 
with each other. Thus, one can differentiate at least three major response groups, treatments without the addition of flours of animal origin, the BMBM (control diet $+4.5 \%$ BMBM) and YEAST (control diet + yeast) treatments and the other treatments supplemented with BMBM (control diet $+4.5 \%$ BMBM). This distinction could not be visualised when the confidence regions were formed, which demonstrates the importance of performing the discriminant analysis.

At day 56, the CONTROL (control diet), YEAST (control diet + yeast), BMBM + GLUTEN (control diet $+4.5 \%$ BMBM + corn gluten), BMBM + YEAST (control diet $+4.5 \% \mathrm{BMBM}+$ yeast) and BMBM + GLUTEN + YEAST (control diet + $4.5 \%$ BMBM + corn gluten + yeast) groups formed response groups with their respective samples without the influence of other groups. The GLUTEN (control diet + corn gluten) response group was formed by the GLUTEN (control diet + corn gluten), GLUTEN + YEAST (control diet + corn gluten + yeast) and BMBM (control diet $+4.5 \%$ BMBM) samples. The GLUTEN + YEAST (control diet + corn gluten + yeast) group formed a response group with samples of GLUTEN (control diet + corn gluten) and GLUTEN + YEAST (control diet + corn gluten + yeast), and the BMBM (control diet $+4.5 \%$ BMBM) response group was formed by the BMBM (control diet $+4.5 \%$ BMBM) and GLUTEN (control diet + corn gluten) samples. Therefore, at this point in time, three major response groups were also formed, as follows: control diet, diets with BMBM supplemented with gluten and/or yeast and diets containing gluten and/or yeast and diets containing meat and bone meal.

The MANOVA of the yolk at day 28 of sampling (Figures 2A and 2C) showed that all treatments


Figure 2 - The confidence regions formed by the difference between the $\delta^{13} \mathrm{C}$ and $\delta^{15} \mathrm{~N}$ isotope values of the yolks in each treatment group compared to the control treatment group $(n=8)$. A) 28 days; B) 56 days; C) 28 days; D) 56 days. 
differed significantly from the control; however, the GLUTEN and YEAST (control diet + yeast) treatments were different only for carbon-13. At day 56 of sampling (Figure 2B and D), all experimental treatments differed from the control group for both isotopes.

The discriminant analysis of the yolk at day 28 of sampling indicated that the response groups were not well defined and suggested that a period of 28 days after changing the diet may not be long enough for a total imprinting of the isotope signal in the egg yolks. However, at day 56 of sampling, the response groups of CONTROL, YEAST (control diet + yeast), BMBM + GLUTEN (control diet + $4.5 \%$ BMBM + corn gluten), BMBM + YEAST (control diet + 4.5\% BMBM + yeast) and BMBM + GLUTEN + YEAST (control diet $+4.5 \%$ BMBM + corn gluten + yeast) were formed by their own samples without interference from any other treatment. Only the GLUTEN (control diet + gluten), GLUTEN + YEAST (control diet + corn gluten + yeast) and BMBM (control diet +4.5 $\%$ BMBM) groups included mixtures in the response group. Thus, three response groups were formed, as follows: control, control without the addition of BMBM and diets with BMBM addition.

As regards the albumen, the MANOVA demonstrated that all experimental treatments were significantly different from the CONTROL (control diet) at 28 days (Figure $3 \mathrm{~A}$ and $\mathrm{C}$ ); however, at 56 days (Figure $3 \mathrm{~B}$ and D), the YEAST (control diet + yeast) treatment showed no difference from the CONTROL (control diet).


Figure 3 - The confidence regions formed by the difference between the $\delta^{13} \mathrm{C}$ and $\delta^{15} \mathrm{~N}$ isotope values of the albumens in each treatment group compared to the control treatment group $(n=8)$. A) 28 days; B) 56 days; C) 28 days; D) 56 days. 


\section{Discussion}

The difference between the assessment days was observed in the eggs and its fractions as evidence that the animal is composed of the isotopes it consumes, and exhibits a variation of approximately $2 \%$ for carbon- 13 and $3 \%$ for nitrogen-15 (Hobson et al., 2010), which is an outcome that is corroborated by numerous experiments in poultry (Carrijo et al., 2006; Gottmann et al., 2008; Denadai et al., 2009; Oliveira et al., 2010; Cruz et al., 2012; Kanayama et al., 2012 and Móri et al., 2013).

An enrichment in the isotope values of carbon-13 and nitrogen-15 in the diets was found as a result of the inclusion of BMBM, which was then observed in the eggs and its fractions (Dordevic et al., 2012).

The difference may have been caused by changing the diet on day 28, and not due to the lack of time for a new isotopic impression, as Denadai et al. (2009) evaluated the isotopic turnover in laying hens and found that the total $\delta^{13} \mathrm{C}$ isotopic exchange values varied from 29 to 35 days, depending on the treatment.

At 35 days of feeding, Denadai et al. (2009) assessed the eggs of birds that were given diets with the addition of alternative ingredients and meat and bone meal, and all treatments were significantly different from the control treatment. The difference in outcomes between the assessment days suggests that the feeding of a diet for only 28 days may be insufficient for the total imprinting of the isotope signal in the eggs.

Gottmann et al. (2008), when evaluating the pectoral muscle of 42-day-old broiler chickens, identified the presence of viscera meal $(1.5 \%)$ through multivariate discriminant statistical analysis whereas Oliveira et al. (2010) detected an inclusion of $8 \%$ or more of animal origin meal in the feed of 42-day old broilers through MANOVA.

Franke et al. (2008) used discriminant analysis for authentication of the geographical origin of poultry meat through multi-trace element and oxygen isotope analysis. Discriminant analysis was also performed by Horacek and Min (2010) to differentiate Korean beef by means of carbon, nitrogen and hydrogen isotopes. Guo et al. (2010) applied it to trace the geographic origin of Chinese cattle using carbon and nitrogen isotopes while Sant'Ana et al. (2010) used discriminant analysis to identify wild fish and fish in captivity by means of carbon and nitrogen isotopes.

Heaton et al. (2008) showed that it was possible to determine the origin of beef through multi-isotope analysis. However, the use of a canonical discriminant analysis was useful when data on the origin of the samples to be differentiated were available. The differentiation of samples without prior information could be more complicated (Sartori et al., 2012).

Therefore, the multivariate analyses complemented each other in the differentiation of diets with the addition of BMBM from diets without the BMBM addition. The discriminant analysis at both 28 days and 56 days formed well-defined response groups, which corroborate the studies by Denadai et al. (2009) which stated that albumen was the fraction that best detected the BMBM inclusions even with the addition of other plant-origin ingredients and yeast.

\section{Conclusions}

The stable $\delta^{13} \mathrm{C}$ and $\delta^{15} \mathrm{~N}$ isotope technique can detect in the eggs the BMBM used in the feeding of laying hens, even with the addition of other plant-origin ingredients and yeast.

The period of 28 days of feeding may be insufficient for the imprinting of the isotope signal of the diets in the egg and in the yolk; however, it proved to be long enough for detection in the albumen.

\section{Acknowledgments}

To São Paulo Research Foundation (FAPESP) for the scholarship postdoc granted to the first author and financial support FAPESP process number 2008/57411-4 for project execution.

\section{Authors' Contributions}

Conceptualization: Denadai, J.C.; Sartori, J.R. Data acquisition: Denadai, J.C.; Madeira, L.A.; Pizzolante, C.C.; Kakimoto, S.K. Data analysis: Sartori, M.M.P.; Eliodoro, V.E. Design of methodology: Eliodoro, V.E. Writing and editing: Denadai, J.C.; Batistioli, J.S.; Eliodoro, V.E.; Contin Neto, A.C.; Sartori, J.R.

\section{References}

Bellaver, C.; Brum, P.A.R.; Lima, G.M.M.; Boff, J.; Kerber, J. 2001. Partial substitution of soybean meal by poultry offal meal in diets balanced according to protein and total or digestible amino acids for broilers. Brazilian Journal of Poultry Science 3: 233-240 (in Portuguese, with abstract in English).

Carrijo, A.S.; Pezzato, A.C.; Ducatti, C.; Sartori, J.R.; Trinca, L.; Silva, E.T. 2006. Traceability of bovine meat and bone meal in poultry by stable isotope analysis. Brazilian Journal of Poultry Science 8: 63-68.

Chen, M.F.; Huang, C.H. 2013. The impacts of the food traceability system and consumer involvement on consumers' purchase intentions toward fast foods. Food Control 33: 313319.

Cruz, V.C.; Araújo, P.C.; Sartori, J.R.; Pezzato, A.C.; Denadai, J.C.; Polycarpo, G.V.; Ducatti, C. 2012. Poultry offal meal in chicken: traceability using the technique of carbon $\left({ }^{13} \mathrm{C} /{ }^{12} \mathrm{C}\right)$ and nitrogen $\left({ }^{15} \mathrm{~N} /{ }^{14} \mathrm{~N}\right)$-stable isotopes. Poultry Science 91: 478486.

Denadai, J.C.; Ducatti, C.; Sartori, J.R.; Pezzato, A.C.; Móri, C.; Gottmann, R.; Mituo, M.A.O. 2009. Traceability of bovine meat and bone meal in eggs from laying hens fed with alternative ingredients. Pesquisa Agropecuária Brasileira 44: 1-7 (in Portuguese, with abstract in English). 
Dordevic, N.; Wehrens, R.; Postma, G.J.; Buydens, L.M.C.; Camin, F. 2012. Statistical methods for improving verification of claims of origin for Italian wines based on stable isotope ratios. Analytica Chimica Acta 757: 19-25.

Franke, B.M.; Hadorn, R.; Bosset, J.O.; Gremaud, G.; Kreuzer, M. 2008. Is authentication of the geographic origin of poultry meat and dried beef improved by combining multiple trace element and oxygen isotope analysis? Meat Science 80: 944-947.

Gottmann, R.; Pezzato, A.C.; Ducatti, C.; Denadai, J.C.; Móri, C.; Mituo, M.A.O.; Sartori, J.R. 2008. Traceability of animal byproducts in diets containing yeast and wheat meal for broilers. Pesquisa Agropecuária Brasileira 43: 1641-1647 (in Portuguese, with abstract in English).

Guo, B.L.; Wei, Y.M.; Pan, J.R.; Li, Y. 2010. Stable C and N isotope ratio analysis for regional geographical traceability of cattle in China. Food Chemistry 118: 915-920.

Heaton, K.; Kelly, S.D.; Hoogewerff, J.; Woolfe, M. 2008. Verifying the geographical origin of beef: the application of multi-element isotope and trace element analysis. Food Chemistry 107: 506-515.

Hobson, K.A.; Barnett-Johnson, R.; Cerling, T. 2010. Using isoscapes to track animal migration. p. 273-298. In: West, J.B.; Bowen, G.J.; Dawson, T.E.; Tu, K.P., eds. Isoscapes. Springer, Dordrecht, The Netherlands.

Horacek, M.; Min, J.S. 2010. Discrimination of Korean beef from beef of other origin by stable isotope measurements. Food Chemistry 121: 517-520.

Kanayama, J.S.; Pezzato, A.C.; Sartori, J.R.; Ducatti, C.; Novaes, V.H.C.; Fascina, V.B.; Carvalho, F.B. 2012. Traceability of animal by product meals in broilers fed sugarcane yeast using stable isotopes. Brazilian Journal of Poultry Science 14: 51-55.

Madeira, L.A.; Denadai, J.C.; Ducatti, C.; Pezzato, A.C.; Araújo, P.C.D.; Sartori, M.M.P.; Sartori, J.R. 2015. Assessment of low amounts of meat and bone meal in the diet of laying hens by using stable isotopes. Semina: Ciências Agrárias 36: 1155-1168.
Menozzi, D.; Halawany-Darson, R.; Mora, C.; Giraud, G. 2015. Motives towards traceable food choice: a comparison between French and Italian consumers. Food Control 49: 40-48.

Móri, C.; Ducatti, C.; Pizzolante, C.C.; Kakimoto, S.K.; Denadai, J.C. 2013. Traceability of animal meals in Japanese quail eggs using the technique of ${ }^{13} \mathrm{C}$ and ${ }^{15} \mathrm{~N}^{*}$ stable isotopes. Brazilian Journal of Poultry Science 15: 59-64.

Oliveira, R.P.; Ducatti, C.; Pezzato, A.C.; Denadai, J.C.; Cruz, V.C.; Sartori, J.R.; Caldara, F.R. 2010. Traceability of poultry offal meal in broiler feeding using isotopic analysis $\left(\delta^{13} \mathrm{C}\right.$ and $\delta^{15} \mathrm{~N}$ ) of different tissues. Brazilian Journal of Poultry Science 12: 13-20.

Rostagno, H.S.; Albino, L.F.T.; Donzele, J.L.; Gomes, P.C.; Oliveira, R.D.; Lopes, D.C.; Euclides, R.F. 2011. Food Composition and Nutritional Requirements: Brazilian Tables for Poultry and Pigs = Composição de Alimentos e Exigências Nutricionais: Tabelas Brasileiras para Aves e Suínos Viçosa, UFV, MG, Brazil (in Portuguese).

Sant'Ana, L.S.; Ducatti, C.; Ramires, D.G. 2010. Seasonal variations in chemical composition and stable isotopes of farmed and wild Brazilian freshwater fish. Food Chemistry 122: 74-77.

Sartori, M.M.P.; Denadai, J.C.; Gracia, A.M.L.; Carrijo, A.S.; Ducatti, C. 2012. Multivariate analysis of stable isotope data in the traceability process for birds. Acta Scientiarum. Animal Sciences 34: 437-442.

Verbeke, W.; Ward, R.W. 2006. Consumer interest in information cues denoting quality, traceability and origin: an application of ordered probit models to beef labels. Food Quality and Preference 17: 453-467. 